\title{
DIELECTRIC PROPERTIES OF MALEIC ANHYDRIDE MODIFIED UNSATURATED POLYESTER COMPOSITES REINFORCED WITH CHICKEN FEATHER FIBRE
}

\author{
S. Hamdan*, K. S. Kiew and M. R. Rahman \\ Faculty of Engineering, Universiti Malaysia Sarawak, \\ 94300 Kota Samarahan Sarawak, Malaysia \\ Email: hsinin@feng.unimas.my
}

\begin{abstract}
Unsaturated polyester matrix modified with maleic anhydride is loaded with different chicken feather fibre loadings from $0 \%$ to $40 \%$. The composite materials were exposed for dielectric study in a wide range of frequencies from $60 \mathrm{~Hz}$ to $1 \mathrm{MHz}$. All of the composite materials exhibited the characteristics of having high dielectric values at lower frequencies, which gradually reached significantly lower values at higher frequencies. This composite material appeared to have good stability of dielectric properties at a high frequency of $1 \mathrm{MHz}$, and can be potentially proposed for use as a high-speed printed circuit board (PCB) material. FTIR analysis indicates high compatibility between maleic anhydride and unsaturated polyester, to form strong bonding with the hydroxyl group of the fibre. SEM analysis specifies the good penetration of the monomer to the cell wall, eliminating voids on the matrix.
\end{abstract}

Keywords: Dielectric properties; chicken feather fibre; bio-composite; unsaturated polyester; maleic anhydride

\section{INTRODUCTION}

Fibres are one of the main components for polymer-matrix composites. Although the market is dominated by the utilization of synthetic fibre, there is an increasing trend in research that is focusing on the use of natural fibres [1-8]. The composite industry has been influenced to change from synthetic fibres to natural fibres due to increasing environmental concerns and energy consumption from processing traditional synthetic fibres. Natural fibres provide advantages such as biodegradability, ease of availability, relatively low cost and a good specific properties-to-density ratio [9-12]. Natural fibres, particularly plant fibres, have been a major interest for most researchers. On the other hand, fewer studies have been done on keratin fibres, including chicken feather fibre. In the US alone, the poultry industry produces 50.4 billion pounds of chicken annually (USDA). The annual production of chicken feathers will be 3.5 billion pounds if $6 \%$ of the bird's weight is feather [13]. The feather is considered as waste and is usually disposed of either by burning or as landfill, which is considered an expensive process and not environmentally friendly [13]. The proposed solution is to utilize chicken feather as reinforcement in composites to offer an environmental solution for feather disposal. Among the vertebrates, feathers are the most complex appendage. Feathers have a low density of $0.8 \mathrm{~g} / \mathrm{cm}^{3}$ while having good thermal, mechanical and insulation properties [14-16]. These properties result from the air pockets within the protein filaments of the feather [9]. Therefore, chicken feather is suitable for the application of 
low load bearing composites such as interior panelling or ready-to-assemble furniture, where qualities such as bulk quantity, low cost and lightweight are desirable $[9,14,16]$. Currently, there is limited research focusing on chicken feather, which indicates that more research needs to be conducted to exploit the ease of availability and relatively low cost of the chicken feather fibre.

The chicken feather can mainly be separated into two parts, the quill and the fibre [13]. The keratin takes the form of fibre keratin and quill keratin, the two forms of microcrystalline keratin in the feathers [17]. The quill is a hard and dense central stem while the fibre is of soft fibre branches from the quill stem. Both the quill and the fibre can be utilized as reinforcement in composites [14, 18]. Uzun and co-workers [14] have attempted using thermoset as matrix to produce chicken feather based composites, namely vinyl ester and polyester. They investigated the impact of vinyl ester and polyester on the behaviour of composites at $10 \%$ of chicken feather fibre, which were improved by $25 \%$ and $300 \%$ respectively. Reddy and Yang [18] have been experimenting with ground chicken feather quill (processed) and whole chicken feathers (raw) to couple with polypropylene composite. They ascertain that the whole chicken feather is better than processed chicken feather in terms of acoustic, flexural and tensile properties. Besides, the amino acid sequence of feather keratin from chicken feather contains $60 \%$ hydrophobic amino acids and 40\% hydrophilic amino acids [16]. This allows the chicken feather to have some compatibility with thermoplastics such as polyethylene, polypropylene or thermosets such as epoxy resin and polyester resin. Recently, Bullions, Gillespie [19] used maleic anhydride modified polypropylene to increase polypropylene/keratin fibre interactions. There is an increasing interest in utilizing chicken feather fibre as a dielectric material due to its hollow honeycomb structure that contains air, which provides an optimum dielectric value at 1.0 [20]. The research conducted by Zhan and co-workers Zhan and Wool [13], [20] realizes the promising potential of chicken feather fibre for electronic applications, where its dielectric properties are generally comparable to or lower than those of commercial PCBs. Unsaturated polyester (UP) is easily available and hydrophobic in nature. It can be coupled with chicken feather fibre to produce composite due to limited research on investigating the resulting properties with other thermoset resins such as epoxy [13]. Maleic anhydride has been commonly utilized by researchers [21-24] to improve the bonding between natural fibres and thermoplastics such as polypropylene and polyethylene. A better bonding creates hindrance in the dipoles movement, leading to the increase of the dielectric relaxation time. In this paper, a type of chicken feather called semiplume feather is used as the reinforcement fibre by incorporating it into UP matrix at varying fibre loadings from 0 to $40 \mathrm{wt} \%$ to determine the influence of chicken feather fibre loading and the frequency on chicken feather/polyester composites. In addition, the polymer matrix is modified with maleic anhydride to show the effects on the electrical resistivity and permittivity resulting from the changes in composite fibrematrix adhesion.

\section{Materials}

\section{MATERIALS AND METHODS}

The matrix material used in this study was based on the UP with the trade name "Reversol P9509". For curing, the matrix was mixed with a curing catalyst, namely methyl ethyl ketone peroxide (MEKP) at a concentration of $1 \%$ by weight ratio of the matrix. The maleic anhydride with molecular weight of $98.06 \mathrm{~g} / \mathrm{mol}$ is supplied by 
Aldrich. Chicken feathers were obtained from a local poultry farm and used as reinforcement after processing. All other chemicals used were of analytical grade obtained from local commercial sources.

\section{Chicken Feather Fibre}

The chicken feathers were obtained from a local poultry farm. Generally, there are contour feathers, down feathers and semiplume feathers that can be used as reinforcement fibre. The chicken feathers were soaked, washed in a water-soluble ethanol and sun-dried for $7 \mathrm{~h}$. To make sure that the materials were completely dried, the chicken feathers were left in a furnace at $80^{\circ} \mathrm{C}$ for $24 \mathrm{~h}$. For this experiment, the semiplume feather as shown in Figure 1 was used as reinforcement. The growing phase of the feather starts from down feather to semiplume feather, before reaching maturity stage to become contour feather. The semiplume feather possesses the characteristics of both down feather and contour feather [25]. The down feathers obtained after the convection oven were cut into sizes of approximately $3-6 \mathrm{~mm}$.

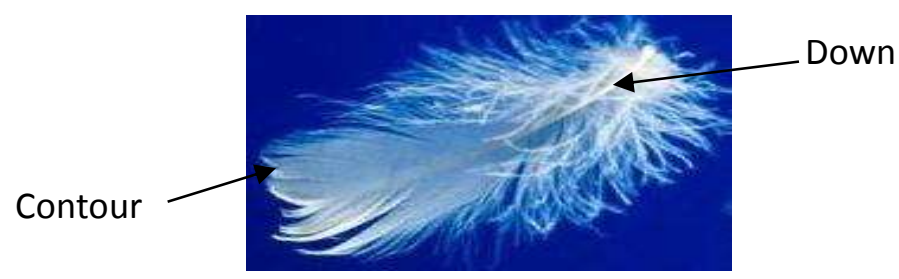

Figure 1. Semiplumefeather.

\section{Specimen Preparation Method}

The matrix material, UP, was modified with maleic anhydride with a molecular weight of $98.06 \mathrm{~g} / \mathrm{mol}$. $1 \mathrm{wt} \%$ of maleic anhydride was added to $1000 \mathrm{ml}$ of UP by mixing at $50 \mathrm{rpm}$ at room temperature for $1 \mathrm{~h}$ until the maleic anhydride was completely dissolved into the matrix. The modified UP resin was then bottled and stored under ambient temperature before the experiment. The proposed chemical reaction between maleic anhydride and UP is shown in Figure 2. UP reinforced with chicken feather fibre (CFF) composites and maleic anhydride modified UP reinforced with chicken feather fibre (MACFF) composites were fabricated by resin transfer moulding (RTM). The dried chicken feather fibres were weighed to give $0 \mathrm{wt} \%, 10 \mathrm{wt} \%, 20 \mathrm{wt} \%, 30 \mathrm{wt} \%$ and $40 \mathrm{wt} \%$. Randomly dispersed chicken feather fibres were placed in the first half of the mould (female mould), while the other half of the mould (male mould) was clamped over the top. The chicken feather fibre was taken through a preform process by pressing into the mould shape before the resin was injected. After this preforming, the mould was closed, clamped and UP resin mixed with 1wt\% of methyl ethyl ketone peroxide (MEKP) was injected at an optimum pressure of $1 \mathrm{~kg} / \mathrm{cm}^{2}$. Vacuum was applied simultaneously during the resin impregnation to drive the resin through the cavity to reduce the formation of voids. The hardening of the composite was carried out at room temperature for $6 \mathrm{~h}$. The composites were post cured at $80^{\circ} \mathrm{C}$ in a convection oven for $3 \mathrm{~h}$. A mould with a single cavity is employed throughout the process. For each composite with different fibre loadings, five specimens were produced. 

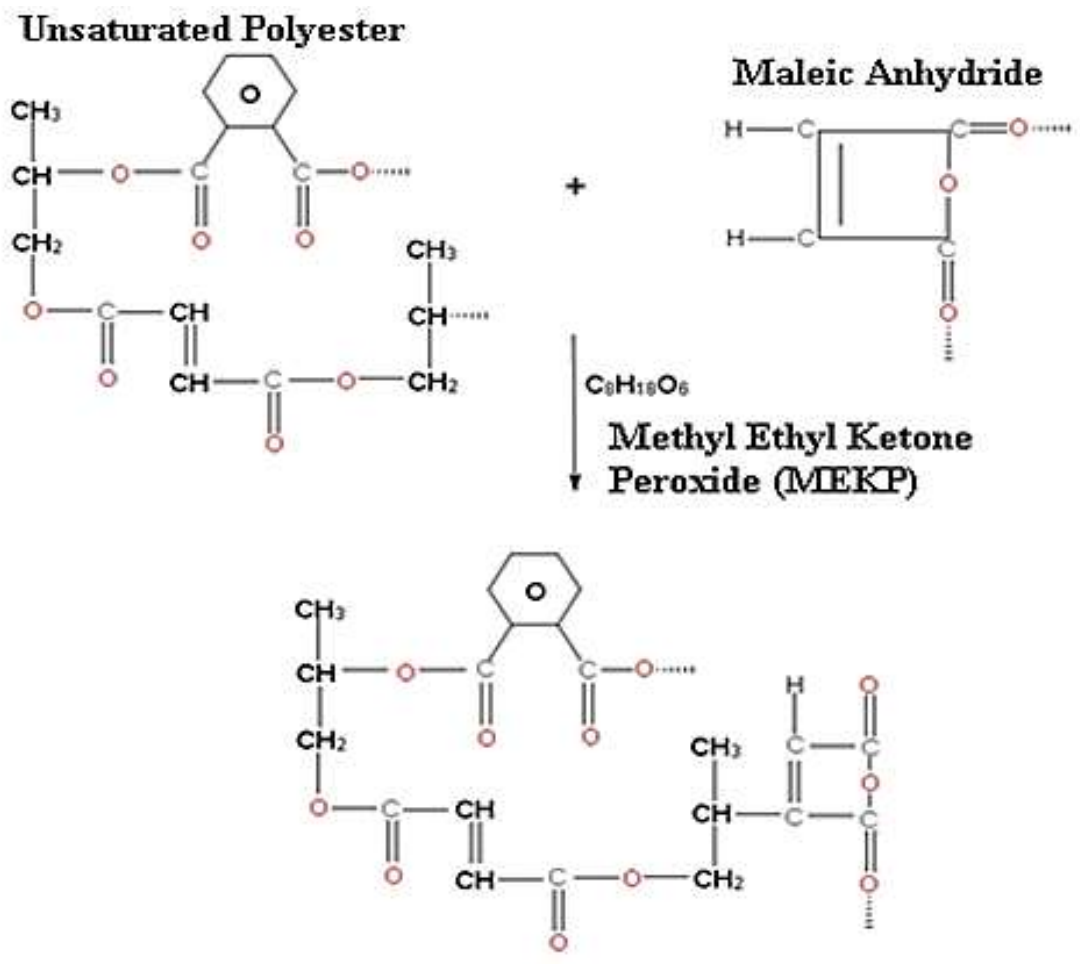

Figure 2. Hypothetical formulation of unsaturated polyester matrix modification with maleic anhydride.

\section{Microstructural Analysis}

The specimens were first fixed with Karnovsky's fixative and then taken through a graded alcohol dehydration series. Once dehydrated, the specimens were coated with a thin layer of gold and then viewed on a scanning electron microscope (JSM6701F) supplied by JEOL, Japan. The specimens were viewed perpendicular to the composite surfaces. The micrographs were taken at a magnification of 500X. XRD analysis was conducted to study the morphological properties of the modified UP composites. A PANalytical XRD diffractometer was used, where $\mathrm{Cu} K \alpha(\lambda=0.1546 \mathrm{~nm})$ radiation was employed with $2 \theta$ varying between $5^{\circ}$ and $80^{\circ}$ at $5^{\circ} / \mathrm{min}$.

\section{Dielectric Analysis}

The dielectric properties of the CFF and MACFF composites were measured with an HP 16451B dielectric test fixture and an HP LCR impedance analyser at frequencies of $60 \mathrm{~Hz}, 1 \mathrm{kHz}, 10 \mathrm{kHz}, 100 \mathrm{kHz}$ and $1000 \mathrm{MHz}$. The composites and actual fibre content $(\%)$ is presented in Table 1 . The specimens fabricated were disc-shaped with a diameter of $50 \mathrm{~mm}$ and a thickness of $5 \mathrm{~mm}$. The samples have flat surfaces and low compressibility. The accuracy of the measurement can be enhanced when analysed through the contacting electrode method. All the specimens were dried in a convection oven at $80^{\circ} \mathrm{C}$ for $3 \mathrm{~h}$ and stored in a dry container before tests. The average value was recorded by the HP impedance analyser after the samples had been tested 10 times at a given frequency. The HP dielectric test fixture measured the capacitance of the specimens. The dielectric constant $\left(\varepsilon_{\mathrm{r}}\right)$ can be calculated from the following equation:

$$
\varepsilon_{\mathrm{r}}=(t C) /\left(\pi r^{2} \varepsilon_{\mathrm{o}}\right)
$$


where $t$ is the thickness of the specimen, $C$ is the equivalent parallel capacitance value; $r$ is the radius of the test specimen and $\varepsilon_{0}$ is the dielectric constant of the free space. The dissipation factor (tan $\delta$,or loss tangent) can be obtained directly from the HP impedance analyser. The dielectric loss can be obtained by multiplying the dissipation factor and dielectric constant.

Table 1. The composites and actual fibre content $(\%)$.

\begin{tabular}{|c|c|c|c|}
\hline Sample code & $\begin{array}{c}\text { Actual fibre content } \\
(\%)\end{array}$ & Sample code & $\begin{array}{c}\text { Actual fibre content } \\
(\%)\end{array}$ \\
\hline $\mathrm{CFFO}^{\mathrm{a}}$ & 0 & $\mathrm{MACFF0}^{\mathrm{b}}$ & 0 \\
\hline CFF10 ${ }^{\mathrm{a}}$ & 12.82 & MACFF $10^{\mathrm{b}}$ & 12.1 \\
\hline $\mathrm{CFF} 20^{\mathrm{a}}$ & 20.81 & MACFF20 & 20.89 \\
\hline $\mathrm{CFF} 30^{\mathrm{a}}$ & 31.67 & MACFF30 & 31.5 \\
\hline $\mathrm{CFF} 40^{\mathrm{a}}$ & 41 & MACFF40 & 38.87 \\
\hline \multicolumn{4}{|c|}{$\begin{array}{l}{ }^{\mathrm{a}} \text { UP reinforced chicken feather fibre (CFF) composite with } 0-40 \% \text { weight volume of } \\
\text { chicken feather fibre. } \\
\text { b Maleicanhydride modified UP reinforced chicken feather fibre (MACFF) composite } \\
\text { with } 0-40 \% \text { weight volume of chicken feather fibre. }\end{array}$} \\
\hline
\end{tabular}

\section{RESULTS AND DISCUSSION}

Scanning electron micrographs (SEM) of CFF and MACFF is shown in Figure 3. From Figure 3(a), the surface of the CFF composite showed voids and an uneven surface. The UP trapped small air bubbles that led to the formation of voids and an uneven surface upon completion of the hardening process. From Figure 3(b), the surface of the MACFF is smooth and has no voids. The smooth surface of MACFF is caused by the good penetration of monomer mixture to bond with UP. This indicated that the maleic anhydride had good compatibility with the UP and infused into the cavities.
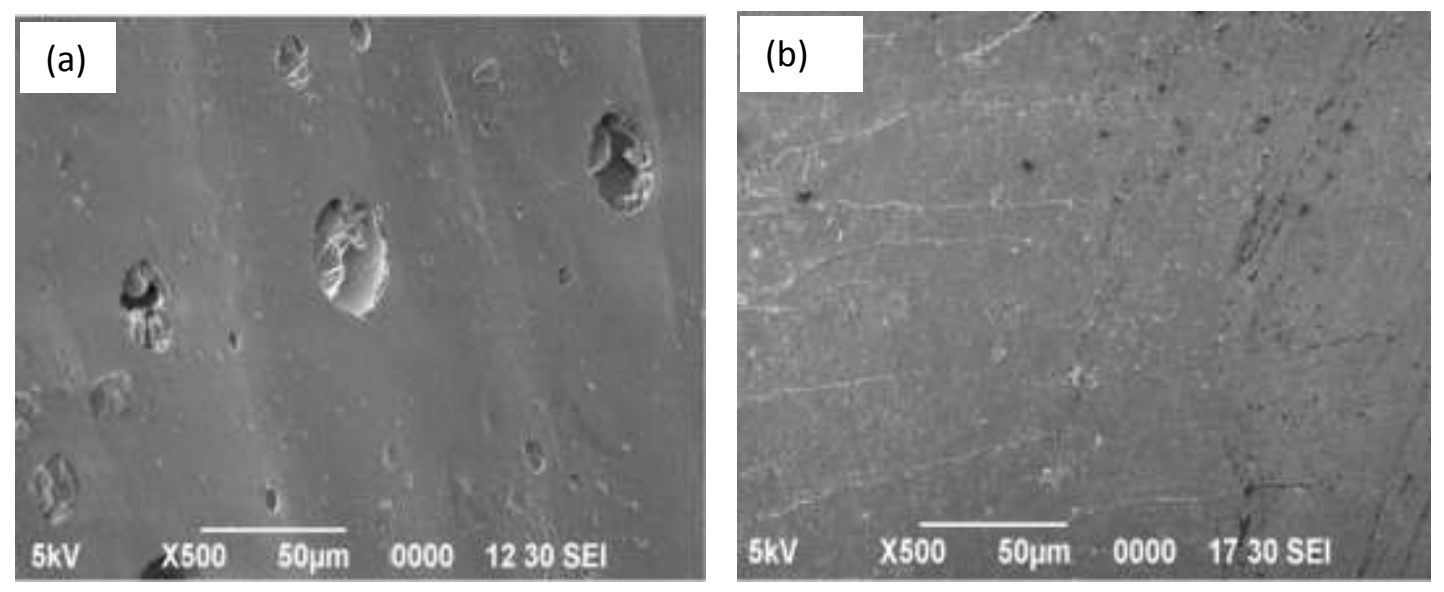

Figure 3. SEM micrographs of (a) CFF and (b) MACFF.

The dielectric properties of polymers are profoundly affected by the changes in crystallinity. In the current work, the diffraction patterns were recorded at $2 \theta$ between $5^{\circ}$ and $80^{\circ}$ to reflect the changes in the degree of crystallinity. The spectrum corresponding to the unmodified UP composite CFF0 (Figure 4(a)) and maleic anhydride modified UP 
composite MACFF0 (Figure 4(b)) shows diffractions peaks at $43^{\circ}$ and $77^{\circ}$ which correspond to the crystallographic planes [111] [110] and [200], respectively [26]. The position of these peaks did not change, which suggests that the structure of modified UP styrene monomer remained the same in comparison with unmodified UP. It is observed that the MACFF0 composite exhibited a new narrow peak at $10.5^{\circ}$ and a broad peak at $19.3^{\circ}$. These values are attributed to the modification of the UP by maleic anhydride.

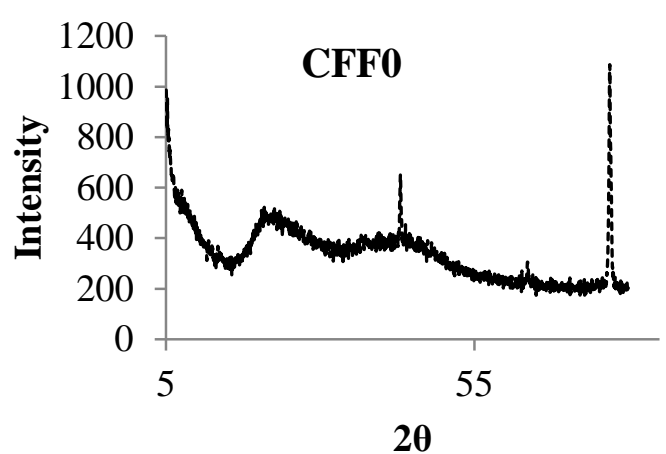

(a)

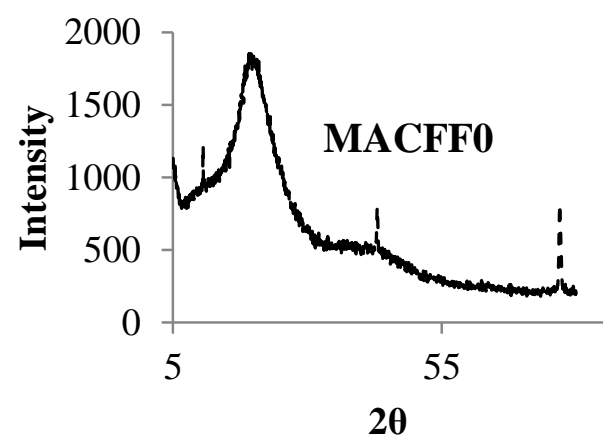

(b)

Figure 4. X-ray diffraction of (a) unmodified UP (CFF0) and (b) maleic anhydride modified UP (MACFF0).
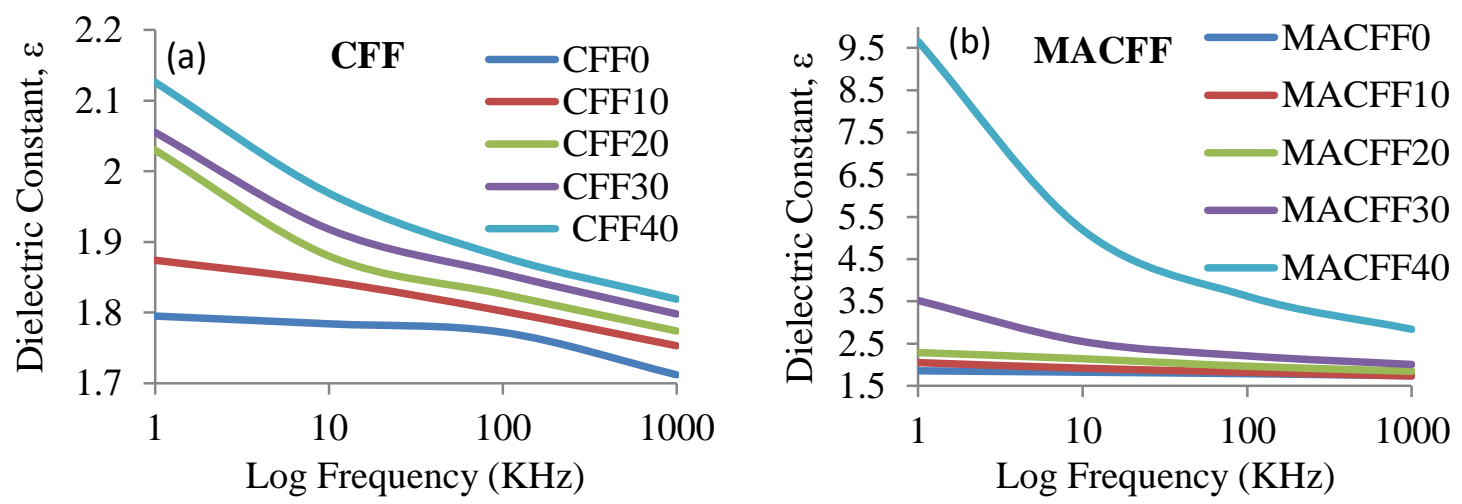

Figure 5. Dielectric constant of (a)CFF and (b)MACFF composite as a function of fibre content and frequency at room temperature.

A material is defined as dielectric if it has the ability to store electric energy when an external electric field is applied. The capacitance with the dielectric material is related to dielectric constant. The variations of dielectric constant with respect to frequency for CFF composites and MACFF composites at different chicken feather fibre loadings are shown in Figure 5. The dielectric constant increases with fibre content over the range of frequencies from $1 \mathrm{kHz}$ to $1000 \mathrm{kHz}$ in the order of CFF0> CFF10> CFF20> CFF30> CFF40 and MACFF0> MACFF10> MACFF20> MACFF30> MACFF40. A similar trend has been observed by Sreekumar, Saiter [27] in plant-based fibre composites. For the composite, the dielectric constant depends on interfacial, orientation, atomic and electronic polarizations [27]. Due to the differences between the UP and the chicken feather fibre, interfacial polarization occurs. The increment of dielectric constant with respect to fibre loading has been attributed to the increment in orientation and interfacial polarizations resulting from the presence of polar groups in the keratin of chicken 
feather fibre. Figure 5(b) shows that MACFF40 has a significant difference in dielectric constant as compared to CFF40 at $1 \mathrm{kHz}$. This is attributed to the increment in orientation and interfacial polarizations resulting from improved adhesive bonding between the matrix and the fibre.

\section{CONCLUSIONS}

In the current work, the scanning electron micrographs of CFF composite showed voids and an uneven surface. The UP trapped small air bubbles that led to the formation of voids and an uneven surface upon completion of the hardening process. On the other hand, the surface of MACFF is smooth and had no voids. The smooth surface of MACFF is caused by the good penetration of monomer mixture to bond with UP. The $\mathrm{X}$-ray diffraction spectrum corresponding to that of the structure of modified UP styrene monomer remained the same as for unmodified UP. It is observed that the MACFF0 composite exhibited a new narrow peak at $10.5^{\circ}$ and a broad peak at $19.3^{\circ}$. These values are attributed to the modification of the UP by maleic anhydride. The dielectric constant increases with fibre content over the range of frequencies from $1 \mathrm{kHz}$ to $1000 \mathrm{kHz}$ in the order of $\mathrm{CFF} 0>\mathrm{CFF} 10>\mathrm{CFF} 20>\mathrm{CFF} 30>\mathrm{CFF} 40$ and MACFF0> MACFF10> MACFF20> MACFF30> MACFF40.

\section{ACKNOWLEDGEMENTS}

The authors would like to acknowledge the Ministry of Higher Education, Malaysia for their financial support, Grant no. ERGS/02(08)/860/2912.

\section{REFERENCES}

[1] Rahman MR, Hasan M, Huque MM, Islam MN. Physico-mechanical properties of jute fiber reinforced polypropylene composites. Journal of Reinforced Plastics and Composites. 2010;29:445-55.

[2] Rahman R, Hasan M, Huque M, Islam N. Physico-mechanical properties of maleic acid post treated jute fiber reinforced polypropylene composites. Journal of Thermoplastic Composite Materials. 2009;22:365-81.

[3] Rahman MR, Huque MM, Islam MN, Hasan M. Mechanical properties of polypropylene composites reinforced with chemically treated abaca. Composites Part A: Applied Science and Manufacturing. 2009;40:511-7.

[4] Rahman MR, Islam MN, Huque MM, Hamdan S, Ahmed AS. Effect Of Chemical Treatment On Rice Husk (Rh) Reinforced Polyethylene (Pe) Composites. BioResources. 2010;5:854-69.

[5] Abdul Majid MS, Daud R, Afendi M, Amin NAM, Cheng EM, Gibson AG, et al. Stress-strain response modelling of glass fibre reinforced epoxy composite pipes under multiaxial loadings. Journal of Mechanical Engineering and Sciences. 2014;6:916-28.

[6] Al-Kayiem HH, Md Yunus Y. Drying of empty fruit bunches as wasted biomass by hybrid solar-thermal drying technique. Journal of Mechanical Engineering and Sciences. 2013;5:652-61.

[7] Hariprasad T, Dharmalingam G, Praveen Raj P. Study of mechanical properties of banana-coir hybrid composite using experimental and fem techniques. Journal of Mechanical Engineering and Sciences. 2013;4:518-31. 
[8] Ibrahim MS, Sapuan SM, Faieza AA. Mechanical and thermal properties of composites from unsaturated polyester filled with oil palm ash. Journal of Mechanical Engineering and Sciences. 2012;2:133-47.

[9] Bullions T, Hoffman D, Gillespie R, Price-O'Brien J, Loos A. Contributions of feather fibers and various cellulose fibers to the mechanical properties of polypropylene matrix composites. Composites Science and Technology. 2006;66:102-14.

[10] Adebisi AA, Maleque MA, Rahman MM. Metal matrix composite brake rotor: Historical development and product life cycle analysis. International Journal of Automotive and Mechanical Engineering. 2011;4:471-80.

[11] Bachtiar D, Sapuan SM, Hamdan MM. Flexural properties of alkaline treated sugar palm fibre reinforced epoxy composites. International Journal of Automotive and Mechanical Engineering. 2010;1:79-90.

[12] Jeffrey KJT, Tarlochan F, Rahman MM. Residual strength of chop strand mats glass fiber/epoxy composite structures: Effect of temperature and water absorption. International Journal of Automotive and Mechanical Engineering. 2011;4:504-19.

[13] Zhan M, Wool RP. Mechanical properties of chicken feather fibers. Polymer Composites. 2011;32:937-44.

[14] Uzun M, Sancak E, Patel I, Usta I, Akalın M, Yuksek M. Mechanical behaviour of chicken quills and chicken feather fibres reinforced polymeric composites. Archives of Materials Science and Engineering. 2011;52:82-6.

[15] Reddy N, Yang Y. Light-weight polypropylene composites reinforced with whole chicken feathers. Journal of applied polymer science. 2010;116:3668-75.

[16] Barone JR. Polyethylene/keratin fiber composites with varying polyethylene crystallinity. Composites Part A: Applied Science and Manufacturing. 2005;36:1518-24.

[17] Hong CK, Wool RP. Development of a bio-based composite material from soybean oil and keratin fibers. Journal of Applied Polymer Science. 2005;95:1524-38.

[18] Reddy N, Yang Y. Properties of natural cellulose fibers from hop stems. Carbohydrate polymers. 2009;77:898-902.

[19] Bullions T, Gillespie R, Price-O'Brien J, Loos A. The effect of maleic anhydride modified polypropylene on the mechanical properties of feather fiber, kraft pulp, polypropylene composites. Journal of applied polymer science. 2004;92:377183.

[20] Zhan M, Wool RP, Xiao JQ. Electrical properties of chicken feather fiber reinforced epoxy composites. Composites Part A: Applied Science and Manufacturing. 2011;42:229-33.

[21] Chand N, Jhod BD. Mechanical, Electrical, and Thermal properties of maleic anhydride modified rice husk filled PVC composites. BioResources. 2008;3:1228-43.

[22] Lee SH, Park J-K, Han JH, Suh KS. Space charge and electrical conduction in maleic anhydride-grafted polyethylene. IEEE transactions on dielectrics and electrical insulation. 1995;2:1132-9.

[23] Abron K, Wahit MUB, Bahraeian S. A study on thermal and electrical properties of high density polyethylene/high density polyethylene grafted maleic anhydride/montmorillonite/polypyrrole blend. Scientific Research and Essays. 2011;6:5895-902. 
[24] Chand N, Nigrawal A, Jain D. Dielectric behavior of maleic anhydride grafted polypropylene (MAgPP) modified sisal fiber reinforced pp composites. Journal of Natural Fibers. 2008;5:270-88.

[25] Bartels T. Variations in the morphology, distribution, and arrangement of feathers in domesticated birds. Journal of Experimental Zoology Part B: Molecular and Developmental Evolution. 2003;298:91-108.

[26] Singha S, Thomas MJ. Dielectric properties of epoxy nanocomposites. Dielectrics and Electrical Insulation, IEEE Transactions on. 2008;15:12-23.

[27] Sreekumar P, Saiter JM, Joseph K, Unnikrishnan G, Thomas S. Electrical properties of short sisal fiber reinforced polyester composites fabricated by resin transfer molding. Composites Part A: Applied Science and Manufacturing. 2012;43:507-11. 